\section{Case Reports in Acute Medicine}

Case Rep Acute Med 2020;3:63-72

DOI: 10.1159/000509712

Published online: August 26, 2020 (c) 2020 The Author(s)

Published by S. Karger AG, Basel www.karger.com/cra

This article is licensed under the Creative Commons Attribution-NonCommercial 4.0 International License (CC BY-NC) (http://www.karger.com/Services/OpenAccessLicense). Usage and distribution for commercial purposes requires written permission.

\title{
Drug Reaction with Eosinophilia and Systemic Symptoms Secondary to Naproxen: A Case Report and Literature Review
}

\author{
Sreethish Sasi ${ }^{a} \quad$ Heba Altarawneh ${ }^{b} \quad$ Mahir A. Petkar ${ }^{c} \quad$ Arun P. Nair $^{d}$ \\ aDepartment of Internal Medicine, Hamad Medical Corporation, Doha, Qatar; \\ ${ }^{b}$ Weil Cornell Medical College, Doha, Qatar; 'Department of Laboratory Medicine \\ and Pathology, Hamad Medical Corporation, Doha, Qatar; ${ }^{d}$ Department of Infectious \\ Diseases, Hamad Medical Corporation, Doha, Qatar
}

\section{Keywords}

Drug hypersensitivity · Drug rash · Eosinophilia

\begin{abstract}
Drug reaction with eosinophilia and systemic symptoms (DRESS) syndrome is a severe adverse drug reaction presenting with rash, fever, lymphadenopathy, and single or multiple organ involvement. It is most commonly associated with antiepileptics, NSAIDs, and sulfa drugs. We report a 40-year-old man who presented with a 1-week history of fever, sore throat, and a diffuse pruritic macular rash that started on the face and trunk before spreading to all extremities 4 weeks after the use of naproxen. He had lymphadenopathy, hepatosplenomegaly, transaminitis, and peripheral eosinophilia. A Registry of Severe Cutaneous Adverse Reactions (RegiSCAR) score of 8 gave a diagnosis of definite DRESS syndrome. Significant resolution of symptoms and laboratory abnormalities were seen after 2 weeks of corticosteroid therapy. DRESS syndrome is a life-threatening condition, and the clinical status of patients can worsen rapidly. Given the high variability in clinical presentation, the diagnosis of DRESS syndrome
\end{abstract}




\section{Case Reports in Acute Medicine}

Case Rep Acute Med 2020;3:63-72

DOI: $10.1159 / 000509712$

(c) 2020 The Author(s). Published by S. Karger AG, Basel www.karger.com/cra

Sasi et al.: DRESS Syndrome Case Report

requires a high degree of suspicion and clinical judgment. Case reports on this entity will equip physicians in acute medicine to recognize and treat the condition early. This report reinforces the importance of using the RegiSCAR score in the diagnosis of DRESS syndrome.

(C) 2020 The Author(s)

Published by S. Karger AG, Basel

\section{Introduction}

Drug reaction with eosinophilia and systemic symptoms (DRESS) syndrome is an idiosyncratic, drug-induced hypersensitivity reaction that presents with skin rash, involvement of internal organs like liver, lung, or kidney, lymphadenopathy, and hematological manifestations such as eosinophilia and atypical lymphocytes. It is a rare condition with an annual incidence of $0.9 / 100,000$ [1]. There is a latency of 2-8 weeks between drug exposure and the onset of skin rash in DRESS syndrome, which is more than in most other drug reactions. The most common culprits are antiepileptics like carbamazepine, lamotrigine, or phenytoin in 35\%, NSAIDs in 13\%, sulfonamides like sulfasalazine, dapsone, trimethoprim-sulfamethoxazole, or sulfadiazine in $12 \%$, antibiotics such as vancomycin, minocycline, or penicillin in $11 \%$, and allopurinol in $6 \%$ of cases [2]. The pathogenesis is complex and multifactorial. We present the case of a young man with no comorbidities who presented with fever, rash, lymphadenopathy, elevated liver enzymes, eosinophilia, and atypical lymphocytes 4 weeks after the use of naproxen.

\section{Case Presentation}

A 40-year-old South Asian man presented to the emergency department with a 1-week history of fever, sore throat, and a diffuse pruritic macular rash that started on the face and trunk before spreading to all extremities. One month before this presentation, the patient had been treated with naproxen $500 \mathrm{mg}$ twice a day for 3 days by a local health center for back pain. On admission he had a low-grade fever, with otherwise stable vitals. Physical examination showed a diffuse maculopapular rash with centrifugal distribution on the head, nape of the neck, and extremities, including palms and soles. The lips were involved, but the oral cavity, conjunctiva, and mucous membranes were spared. There was mild facial edema but no peripheral edema. Nonblanching purpura was noted on the lower limbs with negative Nikolsky sign. The patient's skin lesions on admission are shown in Figure 1. Initial laboratory studies revealed a white blood cell count of $12.4 \times 10^{3} / \mu \mathrm{L}$, with $60 \%$ neutrophils, $30 \%$ lymphocytes, and $4 \%$ eosinophils (Table 1 ). A blood smear showed many pleomorphic atypical reactive lymphocytes. Renal function and electrolytes were normal, and polymerase chain reaction tests for common viral infections were negative. Serological tests for hepatitis and human immunodeficiency viruses were negative. Blood cultures were positive for Staphylococcus epidermidis, which is a common skin contaminant. Malarial smear and echinococcus serology were negative. Autoimmune serology was negative for antimitochondrial, antiliver kidney microsomes, and antinuclear antibodies. Complement levels (C3 and C4) were within normal range. On imaging, the patient had a normal chest X-ray. An abdominal ultrasound showed 


\section{Case Reports in Acute Medicine}

Case Rep Acute Med 2020;3:63-72

DOI: $10.1159 / 000509712$

(c) 2020 The Author(s). Published by S. Karger AG, Basel www.karger.com/cra

Sasi et al.: DRESS Syndrome Case Report

mild hepatomegaly with fatty changes, gallbladder wall thickening, mild splenomegaly, and minimal free fluid in the abdomen. Computed tomography of the abdomen with contrast revealed a bulky spleen with two hypodense lesions. Proximal and mid ascending colon showed mucosal thickening. Echocardiography was normal.

During the emergency department's initial evaluation, the patient received antihistamine, hydrocortisone, and levocetirizine, as drug reaction was suspected. However, he showed no signs of improvement. The fever persisted, reaching as high as $40^{\circ} \mathrm{C}$, and he developed hypoxemia in room air (93\%) with tachypnea. The lactic acid level was $4.2 \mathrm{mmol} / \mathrm{L}$. Sepsis was suspected, and he was started empirically on broad-spectrum coverage with intravenous piperacillin-tazobactam $4.5 \mathrm{~g}$ 8-hourly. On the third day of admission, vancomycin was added as the Gram stain of peripheral blood showed gram-positive cocci in clusters. His clinical condition continued to worsen, and he was admitted to the intensive care unit as the requirement of oxygen went up to $12 \mathrm{~L}$ via a nonrebreather mask. Initial blood cultures were positive for S. epidermidis in one out of four bottles. However, repeated blood cultures were negative, and the labs showed progressive leukocytosis $\left(38 \times 10^{3} / \mu \mathrm{L}\right)$ with eosinophilia $\left(8.9 \times 10^{3} / \mu \mathrm{L}\right)$ as well as increasing bilirubin $(68.0 \mu \mathrm{mol} / \mathrm{L})$, aspartate aminotransferase (449 U/L), alanine aminotransferase (1,564 U/L), and alkaline phosphatase (436 U/L). Antibiotics were stopped after 4 days as clinical history and the Registry of Severe Cutaneous Adverse Reactions (RegiSCAR) score of 8 were suggestive of DRESS syndrome.

A 3-mm skin punch biopsy from the thigh revealed spongiotic epidermis with prominent lymphocytic exocytosis with occasional eosinophils (Fig. 2). The patient was then started on a 2-day course of $40 \mathrm{mg}$ intravenous methylprednisolone followed by a 12-day tapering course of $80 \mathrm{mg}$ oral prednisolone. He showed immediate response to the steroids (Fig. 3) and was discharged on day 14 after normalization of white blood cell count, eosinophil count $(0.3 \times$ $10^{3} / \mu \mathrm{L}$ ), coagulation profile, and improvement of the rash. Elevated liver functions were back to normal during follow-up after 1 month. There was complete resolution of his symptoms by the end of the third week.

\section{Discussion and Conclusion}

Some studies have revealed the genetic association in DRESS syndrome; notably, HLA-B*58:01 is associated with allopurinol hypersensitivity, and HLA-B*13:01 is associated with dapsone hypersensitivity [3,4]. DRESS syndrome occurs as a result of the activation of $\mathrm{T}$ cells specific to each drug, making the reaction drug-specific. It often results in reactivation of viruses, especially human herpesviruses, a phenomenon thought to be due to the expansion of regulatory T cells [5, 6]. Patients usually present with high-grade fever, malaise, and lymphadenopathy, followed by a morbilliform eruption. The eruption spreads rapidly to involve $>50 \%$ of the body surface area and the lesions become confluent, erythematous, and scaled. Facial edema is another classic feature. Most characteristic laboratory abnormalities described in DRESS syndrome are leukocytosis with eosinophilia $>700 \mu \mathrm{L}$, presence of atypical lymphocytes, and elevated alanine aminotransferase [7]. Other clinical and laboratory features depend on the organs involved. The liver is the most commonly involved organ (in up to $86 \%$ of patients) and usually presents as hepatitis, jaundice, or asymptomatic transaminitis. Twenty to thirty percent of patients may have renal involvement presenting in the form of 


\section{Case Reports in Acute Medicine}

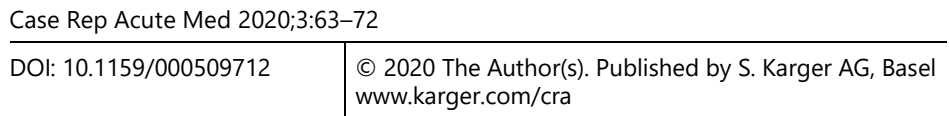

Sasi et al.: DRESS Syndrome Case Report

acute interstitial nephritis. This is most commonly associated with allopurinol. Other organs which might be involved are the lungs (interstitial pneumonitis), heart (eosinophilic myocarditis/pericarditis), gastrointestinal tract (diarrhea and mucosal erosions), pancreas (pancreatitis), thyroid (autoimmune thyroiditis), brain (encephalitis, meningitis), muscle (myositis, increase in creatine kinase), peripheral nerves (polyneuritis), and eyes (uveitis) [8,9]. The histological features of DRESS syndrome are usually nonspecific. The most common patterns observed in skin biopsies of patients with DRESS syndrome include interface dermatitis, spongiosis, vascular damage, and superficial perivascular inflammation. The coexistence of some of these patterns may offer a clue to the diagnosis of DRESS syndrome, albeit with good clinical history and clinicopathological correlation [10].

The European RegiSCAR devised a scoring system based on clinical features, the extent of skin involvement, organ involvement, and clinical course to help clinicians confirm or exclude the diagnosis of DRESS syndrome [11]. Our patient had a RegiSCAR score of 8, which makes him a case of definite DRESS syndrome (Table 2). Identification and prompt withdrawal of the offending drug is the mainstay of treatment. Those with exfoliative dermatitis require fluid, electrolyte, and nutritional support. In a case series, complete recovery was reported in patients without severe organ involvement treated with only supportive care, including topical corticosteroids. In such patients, it is unclear whether systemic corticosteroids shorten the clinical course [12]. Systemic corticosteroids are of unproven benefit for most forms of drug hepatotoxicity, and there is no consensus on their use [13]. However, in our case, the patient showed excellent clinical response with the initiation of systemic corticosteroids. Given the high variability in the clinical presentation, the diagnosis of DRESS syndrome in many cases requires a high degree of suspicion and clinical judgment.

There are reports of relapses induced by the introduction of new drugs, particularly betalactam antibiotics. However, it is not clear whether these were relapses or evolution of the natural course of DRESS syndrome. In our case, the clinical course initially worsened when he was treated with beta-lactams. Hence, we would recommend avoiding treatment with betalactam antibiotics during the course of DRESS syndrome.

\section{Acknowledgment}

The authors would like to acknowledge the Internal Medicine Residency Program for scientific support.

\section{Statement of Ethics}

The case report was approved by the Medical Research Center at Hamad Medical Corporation. Written informed consent was given by the patient to publish his case information, images, and details. The consent form is available from the corresponding author and can be produced on request from the editors. 
Case Reports in
Acute Medicine

Case Rep Acute Med 2020;3:63-72

DOI: $10.1159 / 000509712$

(C) 2020 The Author(s). Published by S. Karger AG, Basel www.karger.com/cra

Sasi et al.: DRESS Syndrome Case Report

\section{Conflict of Interest Statement}

The authors have no conflicts of interest to declare.

\section{Funding Sources}

This study was funded by the Qatar National Library.

\section{Author Contributions}

S. Sasi: manuscript writing, manuscript editing, literature review, and patient management. He will act as a study guarantor. H. Altarawneh: manuscript writing and manuscript editing. M.A. Petkar: manuscript review and manuscript editing, histopathology inputs, and images. A.P. Nair: manuscript writing and literature review. All authors read and approved the manuscript.

\section{References}

1 Husain Z, Reddy BY, Schwartz RA. DRESS syndrome: part I. Clinical perspectives. J Am Acad Dermatol. 2013 May;68(5):693.e1-14.

2 Kardaun SH, Sekula P, Valeyrie-Allanore L, Liss Y, Chu CY, Creamer D, et al.; RegiSCAR study group. Drug reaction with eosinophilia and systemic symptoms (DRESS): an original multisystem adverse drug reaction. Results from the prospective RegiSCAR study. Br J Dermatol. 2013 Nov;169(5):1071-80.

3 Hung SI, Chung WH, Liou LB, Chu CC, Lin M, Huang HP, et al. HLA-B*5801 allele as a genetic marker for severe cutaneous adverse reactions caused by allopurinol [published correction in Proc Natl Acad Sci USA. 2005 Apr;102(17):6237]. Proc Natl Acad Sci USA. 2005 Mar;102(11):4134-9.

4 Tempark T, Satapornpong P, Rerknimitr P, Nakkam N, Saksit N, Wattanakrai P, et al. Dapsone-induced severe cutaneous adverse drug reactions are strongly linked with HLA-B*13:01 allele in the Thai population. Pharmacogenet Genomics. 2017 Dec;27(12):429-37.

5 Ye YM, Hur GY, Kim SH, Ban GY, Jee YK, Naisbitt DJ, et al. Drug-specific CD4+ T-cell immune responses are responsible for antituberculosis drug-induced maculopapular exanthema and drug reaction with eosinophilia and systemic symptoms syndrome. Br J Dermatol. 2017 Feb;176(2):378-86.

6 Kano Y, Hiraharas K, Sakuma K, Shiohara T. Several herpesviruses can reactivate in a severe drug-induced multiorgan reaction in the same sequential order as in graft-versus-host disease. Br J Dermatol. 2006 Aug; 155(2):301-6.

7 Chen YC, Chiu HC, Chu CY. Drug reaction with eosinophilia and systemic symptoms: a retrospective study of 60 cases. Arch Dermatol. 2010 Dec;146(12):1373-9.

8 Lin IC, Yang HC, Strong C, Yang CW, Cho YT, Chen KL, et al. Liver injury in patients with DRESS: A clinical study of 72 cases. J Am Acad Dermatol. 2015 Jun;72(6):984-91.

9 Peyrière H, Dereure O, Breton H, Demoly P, Cociglio M, Blayac JP, et al.; Network of the French Pharmacovigilance Centers. Variability in the clinical pattern of cutaneous side-effects of drugs with systemic symptoms: does a DRESS syndrome really exist? Br J Dermatol. 2006 Aug;155(2):422-8.

10 Chi MH, Hui RC, Yang CH, Lin JY, Lin YT, Ho HC, et al. Histopathological analysis and clinical correlation of drug reaction with eosinophilia and systemic symptoms (DRESS). Br J Dermatol. 2014 Apr;170(4):866-73.

11 Pannu AK, Saroch A. Diagnostic criteria for drug rash and eosinophilia with systemic symptoms. J Family Med Prim Care. 2017 Jul-Sep;6(3):693-4.

12 Uhara H, Saiki M, Kawachi S, Ashida A, Oguchi S, Okuyama R. Clinical course of drug-induced hypersensitivity syndrome treated without systemic corticosteroids. J Eur Acad Dermatol Venereol. 2013 Jun;27(6):722-6. 
Case Reports in Acute Medicine
Case Rep Acute Med 2020;3:63-72

DOI: $10.1159 / 000509712$

(c)

(C) 2020 The Author(s). Published by S. Karger AG, Basel www.karger.com/cra

Sasi et al.: DRESS Syndrome Case Report

13 Funck-Brentano E, Duong TA, Bouvresse S, Bagot M, Wolkenstein P, Roujeau JC, et al. Therapeutic management of DRESS: a retrospective study of 38 cases. J Am Acad Dermatol. 2015 Feb;72(2):246-52.
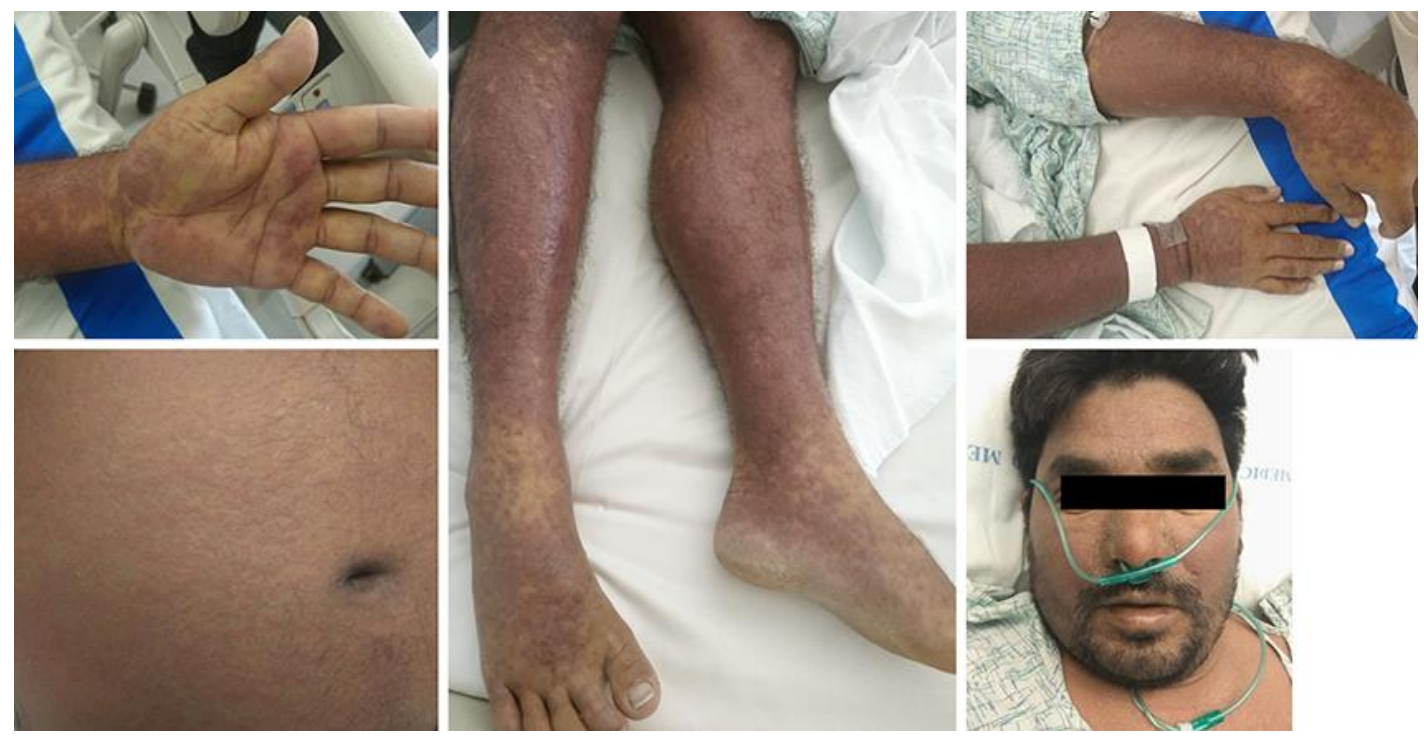

Fig. 1. Clinical images showing the skin lesions at presentation. 


\section{Case Reports in Acute Medicine}

(C) 2020 The Author(s). Published by S. Karger AG, Basel www.karger.com/cra

Sasi et al.: DRESS Syndrome Case Report
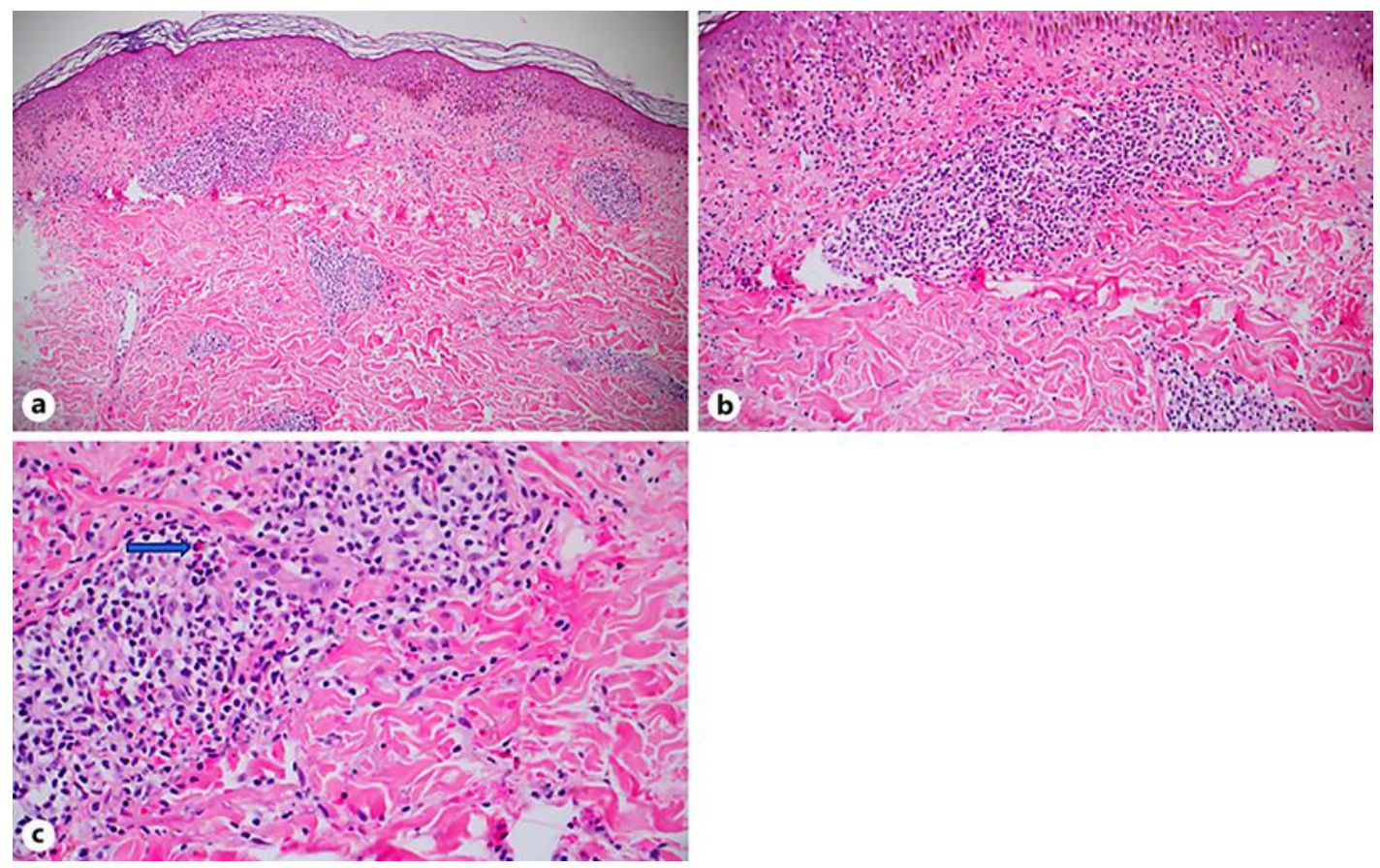

Fig. 2. Histopathological images from skin punch biopsy. a Orthokeratotic epidermis, spongiosis, and interface dermatitis. Note the prominent perivascular and periadnexal chronic inflammatory infiltrate in the dermis. H\&E, $\times 4$. b Higher-power view of the punch biopsy revealing red cell extravasation in the superficial dermis with marked perivascular inflammation. H\&E, $\times 20$. c Scattered eosinophils (blue arrow) were present among the dense inflammation as well as interstitially. H\&E, $\times 40$. 
Case Reports in Acute Medicine
Case Rep Acute Med 2020:3:63-72

DOI: $10.1159 / 000509712$

(C) 2020 The Author(s). Published by S. Karger AG, Basel www.karger.com/cra

Sasi et al.: DRESS Syndrome Case Report

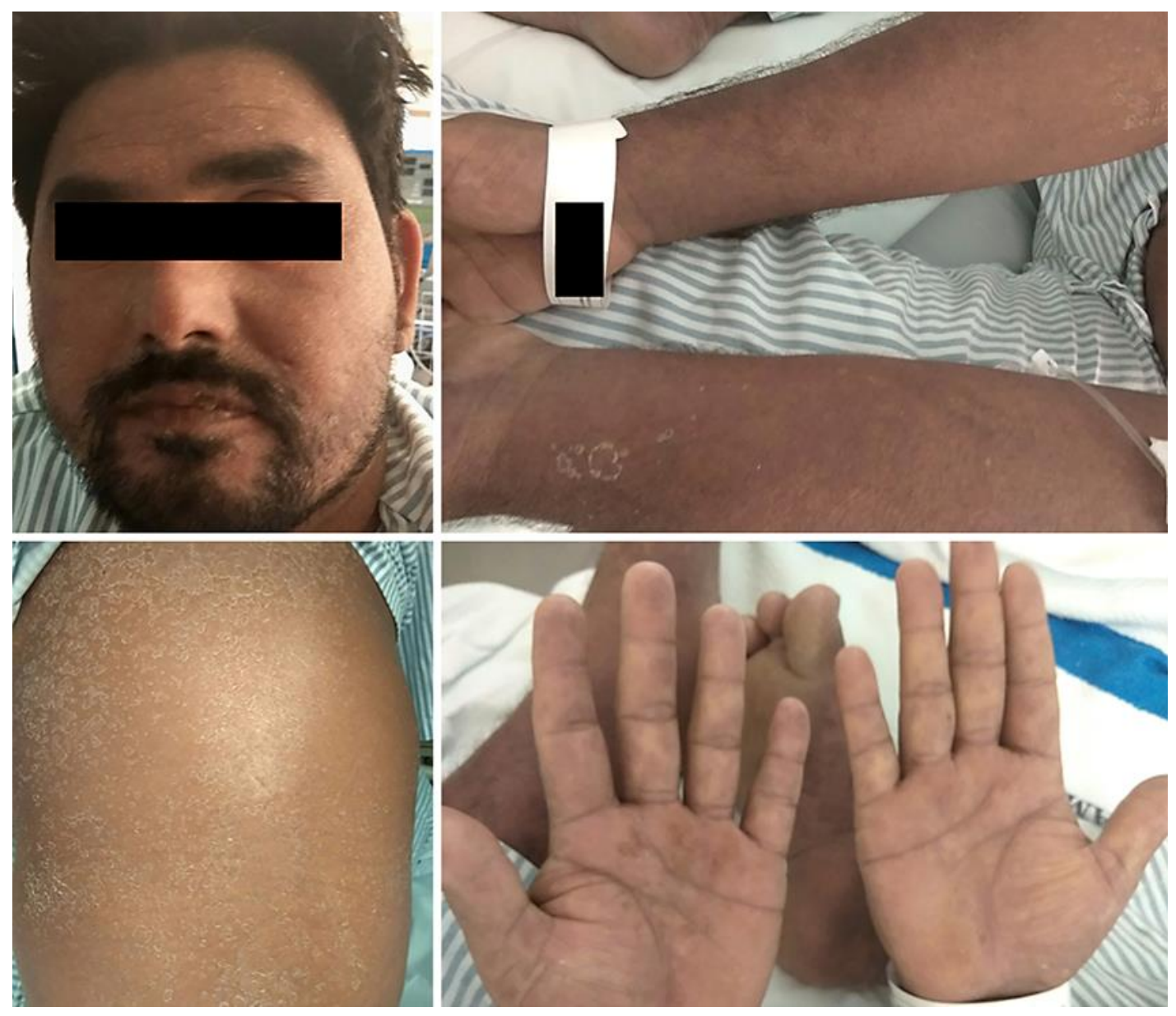

Fig. 3. Clinical images showing the resolution of skin lesions after systemic corticosteroid therapy. 
Sasi et al.: DRESS Syndrome Case Report

Table 1. Results of relevant laboratory tests on admission, during hospital stay, and at discharge

\begin{tabular}{lcccc}
\hline & \multicolumn{2}{l}{ Result } & & \multirow{2}{*}{$\begin{array}{l}\text { Normal } \\
\text { range }\end{array}$} \\
\cline { 2 - 3 } & admission & hospital stay & discharge & \\
\hline Complete blood count & & & & \\
White blood cells, $\times 10^{3} / \mu \mathrm{L}$ & 12.4 & 31.8 & 7.3 & $4-10$ \\
Red blood cells, $\times 10^{6} / \mu \mathrm{L}$ & 5.3 & 4.4 & 4 & $4.5-5.5$ \\
Platelets, $\times 10^{3} / \mu \mathrm{L}$ & 177 & 127 & 251 & $150-400$ \\
Hemoglobin, $\mathrm{g} / \mathrm{dL}$ & 14.1 & 11.7 & 10.9 & $13.0-17.0$ \\
Hematocrit, $\%$ & 41.4 & 34.6 & 33.3 & $40.0-50.0$ \\
Mean corpuscular volume, fL & 98.4 & 78.1 & 82.4 & $83.0-101.0$ \\
Mean corpuscular hemoglobin, pg & 26.7 & 26.3 & 27 & $27.0-32.0$ \\
Mean corpuscular hemoglobin concentration, $\mathrm{g} / \mathrm{dL}$ & 34.1 & 33.7 & 32.7 & $31.5-34.4$ \\
RDW, $\%$ & 14.1 & 15.6 & 20.1 & $11.6-14.5$ \\
Absolute neutrophil count, $\times 10^{3} / \mu \mathrm{L}$ & 7.5 & 14.5 & 10.2 & $2-7$ \\
Lymphocytes, $\times 10^{3} / \mu \mathrm{L}$ & 3.7 & 9.4 & 3.6 & $1-3$ \\
Monocytes, $\times 10^{3} / \mu \mathrm{L}$ & 0.6 & 1.2 & 2.8 & $0.2-1$ \\
Eosinophils, $\times 10^{3} / \mu \mathrm{L}$ & 0.5 & 6.1 & 0.5 & $0-0.5$ \\
Basophils, $\times 10^{3} / \mu \mathrm{L}$ & 0.1 & 0.5 & 0.3 & $0-0.2$ \\
\hline Comprehensive metabolic panel & & & & \\
Urea, mmol/L & 4.4 & 4.9 & 3.6 & $2.8-8.1$ \\
Creatinine, $\mu$ mol/L & 105 & 74 & 68 & $62-106$ \\
Total bilirubin, $\mu$ mol/L & 75 & 175 & 32 & $3.4-20.5$ \\
Alkaline phosphatase, $\mathrm{U} / \mathrm{L}$ & 332 & 463 & 294 & $40-150$ \\
Alanine aminotransferase, $\mathrm{U} / \mathrm{L}$ & 230 & 249 & 265 & $0-55$ \\
Aspartate aminotransferase, $\mathrm{U} / \mathrm{L}$ & 93 & 255 & 50 & $5-34$ \\
C-reactive $p$ rotein, mg/L & 140 & 108 & 33 & $0-5$ \\
\hline
\end{tabular}




\section{Case Reports in}

Acute Medicine

Case Rep Acute Med 2020;3:63-72

DOI: $10.1159 / 000509712$

(C) 2020 The Author(s). Published by S. Karger AG, Basel www.karger.com/cra

Sasi et al.: DRESS Syndrome Case Report

Table 2. Table showing the RegiSCAR score and its components

\begin{tabular}{lll}
\hline Fever $\left(\geq 38.5^{\circ} \mathrm{C}\right)$ & yes & 0 \\
\hline Enlarged lymph nodes $(\geq 2$ sites, $\geq 1 \mathrm{~cm})$ & yes & 1 \\
\hline Atypical lymphocytes & yes & 1 \\
\hline Eosinophilia $(700-1,499$ or $10-19.9 \%)$ & yes & 1 \\
\hline $\begin{array}{l}\text { Skin rash } \\
\quad \text { Extent }>50 \%\end{array}$ & yes & 1 \\
$\quad \begin{array}{l}\text { At least two of: edema, infiltration, purpura, scaling } \\
\text { Biopsy suggesting DRESS syndrome }\end{array}$ & yes & 1 \\
\hline Internal organ involved & yes & 0 \\
\hline Resolution delay & two organs (liver and spleen) & 2 \\
\hline At least three biological investigations done and & $>15$ days & 0 \\
negative to exclude an alternative diagnosis & $\begin{array}{l}\text { yes (antinuclear antibodies, blood } \\
\text { cultures, serology for HAV/HBV/HCV) }\end{array}$ & 1 \\
\hline
\end{tabular}

Total score: 8 (<2 no DRESS syndrome, 2-3 possible DRESS syndrome, 4-5 probable DRESS syndrome, $\geq 6$ definite DRESS syndrome). DRESS, drug reaction with eosinophilia and systemic symptoms; RegiSCAR, Registry of Severe Cutaneous Adverse Reactions. 